\title{
Flash Atomization: A New Concept to Control Combustion Instability in Water-Injected Gas Turbines
}

\author{
Vishwas Iyengar, Harold Simmons, and David Ransom \\ Mechanical Engineering Division, Southwest Research Institute, San Antonio, TX 78228, USA \\ Correspondence should be addressed to Vishwas Iyengar, vishwas.iyengar@swri.org
}

Received 20 July 2011; Revised 1 November 2011; Accepted 15 November 2011

Academic Editor: Constantine D. Rakopoulos

Copyright (๑) 2012 Vishwas Iyengar et al. This is an open access article distributed under the Creative Commons Attribution License, which permits unrestricted use, distribution, and reproduction in any medium, provided the original work is properly cited.

\begin{abstract}
The objective of this work is to explore methods to reduce combustor rumble in a water-injected gas turbine. Attempts to use water injection as a means to reduce $\mathrm{NO}_{X}$ emissions in gas turbines have been largely unsuccessful because of increased combustion instability levels. This pulsation causes chronic fretting, wear, and fatigue that damages combustor components. Of greater concern is that liberated fragments could cause extensive damage to the turbine section. Combustion instability can be tied to the insufficient atomization of injected water; large water droplets evaporate non-uniformly that lead to energy absorption in chaotic pulses. Added pulsation is amplified by the combustion process and acoustic resonance. Effervescent atomization, where gas bubbles are injected, is beneficial by producing finely atomized droplets; the gas bubbles burst as they exit the nozzles creating additional energy to disperse the liquid. A new concept for effervescent atomization dubbed "flash atomization" is presented where water is heated to just below its boiling point in the supply line so that some of it will flash to steam as it leaves the nozzle. An advantage of flash atomization is that available heat energy can be used rather than mechanical energy to compress injection gas for conventional effervescent atomization.
\end{abstract}

\section{Introduction}

The injection of water into gas turbines is not a recent concept. As early as 1903, Ægidius Elling (Bolland and Veer [1]) came up with the idea of spraying water into the air stream before and during the compression process. Wilcox and Trout [2] have also described the benefits of water injection for jet engines. As the pressure to reduce emissions and increase efficiencies and power outputs has mounted in more recent years, further studies have been carried out on ways to inject water by atomizing/spraying.

A number of publications based on work by Lefebvre et al. [3-6] have described a method of liquid fuel atomization commonly referred to as "effervescent atomization". In effervescent atomization, a gas (air in combustion applications) is introduced directly into a flowing liquid upstream of the nozzle exit orifice to create a bubbly two-phase flow. As the liquid flows through the discharge orifice, it is squeezed by the gas bubbles into thin threads and ligaments; the entrained gas bubbles burst as they are released to combustion pressure.
Several researchers have linked insufficient fuel atomization to combustion instability. Chin and Lefebvre [7] demonstrated that in order to achieve better combustion stability, one could inject air into the fuel to achieve improved atomization by effervescence. Golovanevsky and Levy [8] performed an optimization of a combined atomizer and flame holder assembly that is able to suppress the instabilities of the main combustor by generating an additional (controlled) oscillating liquid fueled heat source. The principal idea was to adopt a specially designed effervescent atomizer, driven by the energy of the oscillatory motion of the gas in the unstable combustor for the atomization and distribution of the additional control fuel.

Santoro [9] investigated the specific effects of fuel atomization in combustion instability. In that study, the effects of mean drop size, drop size distribution, and atomization periodicity were examined explicitly with a combustion response model, the results from which indicated that all of these effects were important. It was shown that periodic atomization, in particular, results in large variations in the magnitude 
of the response when the atomization frequency is on the same order as the acoustic oscillation frequency. Yu et al. [10] successfully applied effervescent atomization to mitigate kerosene combustion instability in a supersonic model combustor. Lee et al. [11] also demonstrated that by changing the spray characteristics, it is possible to significantly dampen combustion instabilities. These methods are necessary to a greater extent for heavy fuel applications where effervescent atomization and heating to reduce viscosity is common.

The literature [12-14] establishes that combustor pulsation is improved by finer atomization of fuel sprays. Fuel droplets evaporate, to release combustible gas phase, dependent on temperature and surface area; this process is not uniform with time as droplet size reduces with evaporation. Larger initial droplets or clusters take longer to evaporate and create more distinct and globular regions of enriched fuel air mixture than for smaller droplet sizes. This nonhomogeneous mixture results in chaotic combustion that is amplified by the energy release process and by acoustic resonance. As a result, considerable effort is expended in liquid fuel nozzle design to produce acceptably fine atomization.

The lack of prolific literature $[15,16]$ on water injection suggests less than overwhelming successes in its application; however, there is no reason to expect the evaporation phenomena to be any different from fuel injection except that water will only absorb heat rather than produce it in combustion. In either case, poor atomization can lead to increased combustion dynamics since the flame front is not presented with a homogeneous mixture of water, fuel, and air leading to inconsistent reactivity.

Water fuel emulsion is another method for combustion water injection. It consists of base fuel and water doped with or without a trace content of surfactant. The potential benefit of combustion of emulsion arises from the effect of dilution in both gas and liquid phase reactions and/or from the secondary atomization caused by the vigorous evaporation of the interior liquid, so-called microexplosion. A good review of recent advances in the combustion of water-fuel emulsion is given in [17].

The primary objective of water injection is to mitigate $\mathrm{NO}_{X}$ emissions by reducing combustion peak temperature. For the purposes of this work, it is assumed that the cooling and dilution effects will be reasonably equivalent for water injected as a fine mist or as heavier spray. Thus, the scope of this research was not directed to evaluate $\mathrm{NO}_{X}$ emissions, but solely to explore improved water atomization as a means to minimize combustor pulsation.

\section{Industrial Gas Turbine Experience}

The motivation for this analysis is an industrial gas turbine in cogeneration service that is operated with water injection to reduce $\mathrm{NO}_{X}$ emissions. Emissions are successfully controlled, but chronic combustor rumble problems cause early wear damage at retention devices, crossover tubes, transition piece joints, igniters, and fuel nozzles. Liberated fragments of combustor components and the resulting damage in passing

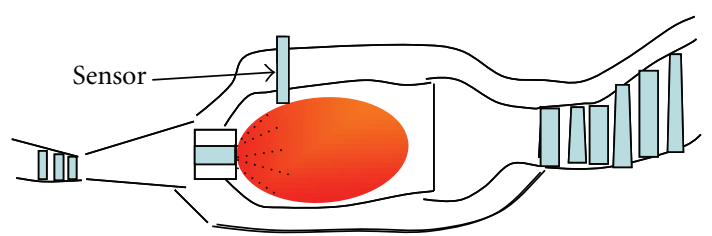

FIGURE 1: Illustration of combustor and pulsation sensor location.

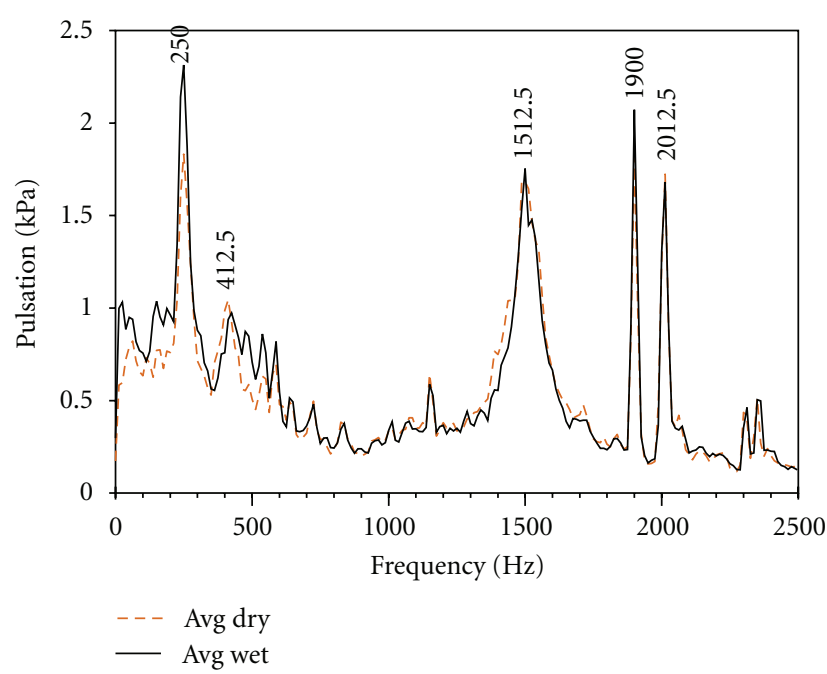

FIGURe 2: Pulsation comparison of the two water flow conditions at $100 \%$ load.

through the turbine is an undoubted deterrent to current water injection technology.

To study the problem, pulsation and vibration sensors are mounted at various locations on the combustor, main fuel lines, and water lines. Figure 1 illustrates the location of the primary sensor used to define internal combustor pulsation; the additional sensors are installed to detect any contributions to combustion pulsation due to flow-induced excitation of the upstream fuel and water supply lines. Testing is performed with the engine operating throughout its normal range of power with and without water injection. The objective is to assess the differences in combustion characteristics with and without water injection over the range of operating loads.

Combustion pulsations are recorded and analyzed at each test point for full water injection (wet) and no water injection (dry). Figure 2 presents a representative comparison of these two conditions at $100 \%$ load.

As can be seen in Figure 2, acoustic response peaks appear at 250,412.5, 1512.5, 1900, and $2012.5 \mathrm{~Hz}$ in the frequency range from zero to $2500 \mathrm{~Hz}$. It is significant that of all these peaks only the $250 \mathrm{~Hz}$ response appears sensitive to water flow variation. This is true for all load conditions tested with a $40 \%$ greater pulsation level for wet versus dry conditions as shown in Figure 3.

Acoustic wave length calculation of the $250 \mathrm{~Hz}$ peak (Figure 2) reveals one-nodal diameter acoustic mode of the 


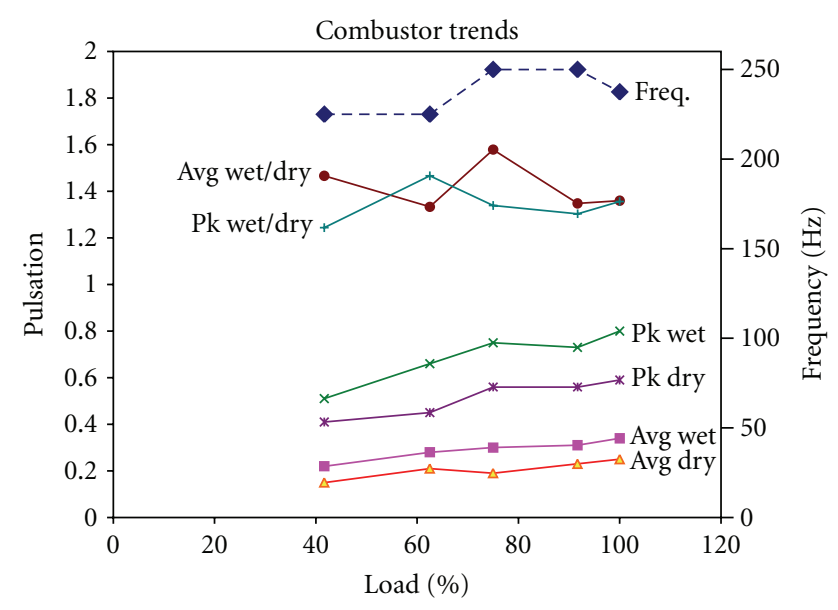

FIgURE 3: Trend of $250 \mathrm{~Hz}$ combustor pulsation versus load.

combustor that results in excitation forces acting on the combustor liners which create damage. A summary of pulsation trends near $250 \mathrm{~Hz}$ in Figure 3 indicates the following. (1) Pulsation with full water injection is about $40 \%$ higher than with no water injection at all load conditions. (2) Pulsation frequency increases at a very slight rate that is not fully consistent with increasing load; the frequency increase from $40 \%$ to $100 \%$ load is less than $25 \mathrm{~Hz}(10 \%)$ for a power increase of $4: 1$.

The water injection introduces dimensions of nonlinearity which are likely players in a noncoherent frequency response exhibited here. This initial testing and further analysis imply that water droplet size may be excessive because the nozzle orifices are too large or the flow velocity is too low. In searching for a solution for this problem, a more extensive investigation is conducted to quantify these effects and to seek methods for improved atomization.

The methods commonly applied to increase atomization include flow velocity, orifice size, air blast, and effervescent atomization.

\section{Flow Velocity and Orifice Size}

Atomization analysis provides valuable insight into the expected jet stream break-up mechanism for a given orifice geometry and flow velocity. The mechanism for a flow stream breaking up into droplets depends on both the diameter of the spray nozzle and the speed of the jet stream leaving the nozzle. Husted et al. [19] provides an excellent summary of four droplet-forming flow regimes as follows. (1) Rayleigh break-up regime-droplet formation occurs far away from the nozzle, and the droplets tend to be larger than the nozzle hole size. (2) First windinduced break-up-droplet formation occurs several nozzle diameters downstream, and the droplets tend to be as the same size as the nozzle hole size. (3) Second wind-induced break-up-droplet formation occurs at short distance from the nozzle, and the droplets tend to be the smaller than the nozzle hole size. (4) Atomization-droplet formation occurs at the nozzle exit, and the droplets tend to be much smaller
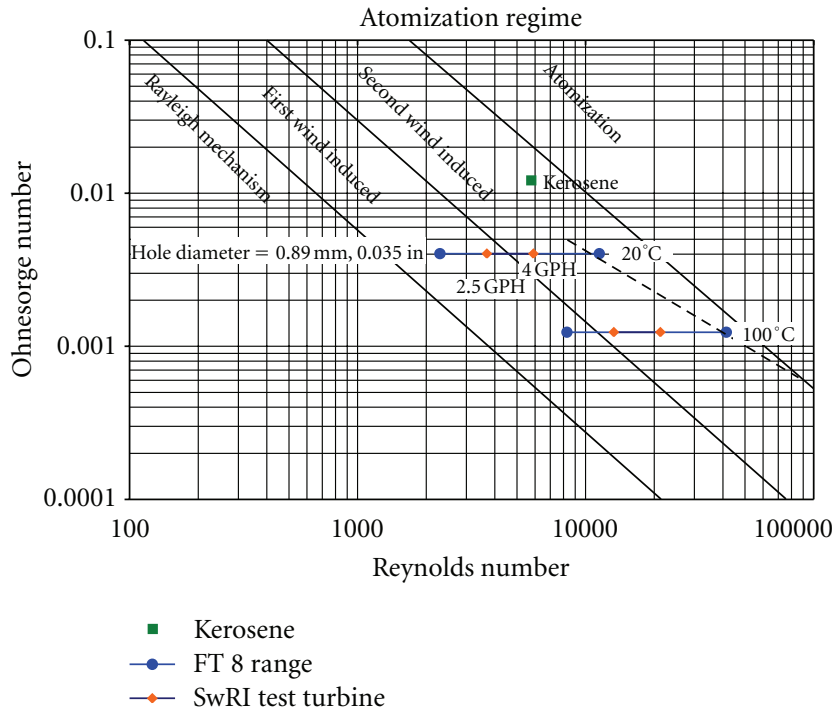

FIgURE 4: Atomization regime analysis.

than the nozzle hole size. Clearly, fine atomization is preferred in order to maximize the droplet surface area. This improves the rate of heat transfer as the droplets evaporate in the hot gas environment.

There are two dimensionless numbers used to evaluate the likely droplet size for a given nozzle geometry, fluid type and flow condition; the Reynolds number and the Ohnesorge number. The Ohnesorge number represents the ratio of viscous forces and the surface tension of the subject fluid. Both are given below:

$$
\begin{gathered}
\mathrm{Re}=\frac{d \nu \rho}{\mu}, \\
\mathrm{Oh}=\frac{\mu}{\sqrt{\rho \sigma d}},
\end{gathered}
$$

where $d$ is the nozzle diameter, $v$ is the fluid velocity, $\rho$ is the fluid density, $\mu$ is the absolute viscosity, and $\sigma$ is the surface tension.

The Re and Oh numbers for the present nozzle are calculated for kerosene at design fuel flow condition $(1.6 \mathrm{~kg} / \mathrm{sec}$ and $\eta t=30 \%)$ and water at minimum and maximum flow conditions $(0.4 \mathrm{~kg} / \mathrm{sec}-2.0 \mathrm{~kg} / \mathrm{sec})$. The water calculations are performed to provide insight to the present concern. The Kerosene calculation is performed to determine if there is a significant difference in the present use and the likely original design condition of the gas turbine fuel nozzle. Figure 4 shows the calculated points and their relationship to the various droplet-forming regimes.

At maximum flow conditions, both points fall within the second wind-induced regime, meaning the droplets are likely to be smaller than the nozzle diameter $(0.84-$ $0.89 \mathrm{~mm}-0.033-0.035$ inches). However, at the minimum flow condition, the water is well within the first windinduced regime, meaning that at lower flow rates, the water should form significantly larger droplets. 


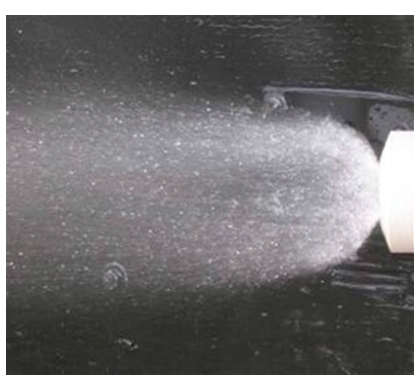

(a) $4.2 \mathrm{~L} / \mathrm{min}$ Flow

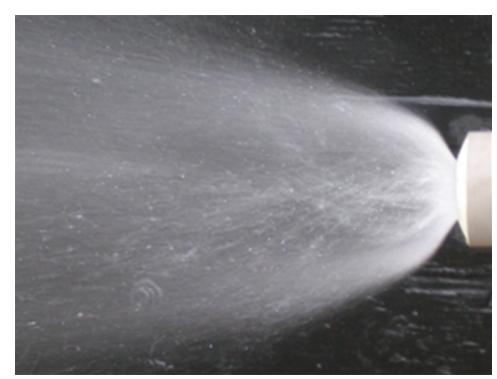

(b) $12.5 \mathrm{~L} / \mathrm{min}$ Flow

FIGURE 5: Visual droplet size comparison conditions corresponding to (a) $30 \%$ power and (b) $100 \%$ load.

It should be noted that viscosity and surface tension are affected by temperature, thus some atomization improvement should be expected by heating. This subtle influence is shown by the dashed line in Figure 4 and is not sufficient to provide the improvement necessary for this application.

\section{Air Blast}

A full-size fuel nozzle incorporating air blast atomization features is tested with water injection in a flow tunnel at atmospheric conditions. The flow tunnel simulates the air blast effect of compressor discharge air that is incorporated in the nozzle which carried the resultant plume downstream, similar to the effect in a combustor. No attempt is made to exactly duplicate the flow stream variation or fuel gas flow that exists in the engine or to quantify droplet sizes, but the test is intended to illustrate the relative effects of water flow variations. Figure 5 presents the extreme results of these tests which relate to the conditions shown in Figure 4 . The lowest water flow rate tested is $4.2 \mathrm{~L} / \mathrm{min}(1.1 \mathrm{gpm})$, and the photograph shows clearly that the droplets are large enough to identify without difficulty. The highest flow rate tested is $12.5 \mathrm{~L} / \mathrm{min}(3.3 \mathrm{gpm})$, and the droplets are clearly much smaller in comparison to the lower flow condition. This test series is clearly in agreement with the prediction for pressure atomization, despite the added influence of the air blast atomization.

\section{Effervescent Atomization}

To explore the potential for enhanced atomization, the water line is injected with high pressure air in an attempt to create an effervescent effect. No attempt is made to create finely distributed bubbles in the stream, rather a simple tee is installed approximately $20 \mathrm{~cm}$ from the nozzle, and air flow is controlled such that a range of volume fraction values is achieved up to 1.5 (air volume/water volume). For the lowest water flow rate $(4.2 \mathrm{~L} / \mathrm{min})$ and the highest volume fraction (1.5), Figure 6 clearly demonstrates much improved atomization over the water only condition for the same water flow rate (Figure 5(a)). However, one of the challenges in mixing liquid and gas phase flows is the tendency of the gas phase to coalesce into larger gas bubbles, resulting in slug flow. Typical methods to combat

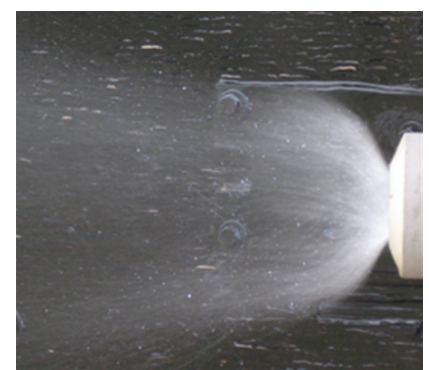

FIGURE 6: Visual droplet size at $4.2 \mathrm{~L} / \mathrm{min}$ water flow with airinjected effervescent atomization.

this behavior are to improve the quality of the mix during the gas injection (bubbly mixing section) and to perform the mixing immediately upstream of the discharge nozzle [7]. In short, the experiment is a success in terms of creating a more atomized flow of water; however, the slug flow experienced in this test is unacceptable and further work would be required to design, test, and fabricate suitable air/water mixing sections. Furthermore, added compression equipment and external energy requirements are costs to be considered.

\section{Flash Atomization}

A unique concept for effervescent atomization dubbed "flash atomization" [18] was developed to overcome the shortcomings of air or gas injection. In flash atomization, water is heated to just below its boiling point in the supply line so that some of it will flash to steam as it leaves the nozzle.

The process is described by reference to Figures 7 and 8 as follows.

(1) The water to be atomized is supplied at position (1) at a pressure $P 1$ and temperature $T 1$.

(2) The water flows through a pipe where it is heated along position (2) to a temperature $T 2$; pressure will reduce to $P 2$ due to flow friction. Heating may be by flame, by electrical heating, by heat exchanger, or by any other process.

(3) The water arrives at the nozzle entrance (2.1) (see Figure 8) at pressure and temperature P2.1 and T2.1. 


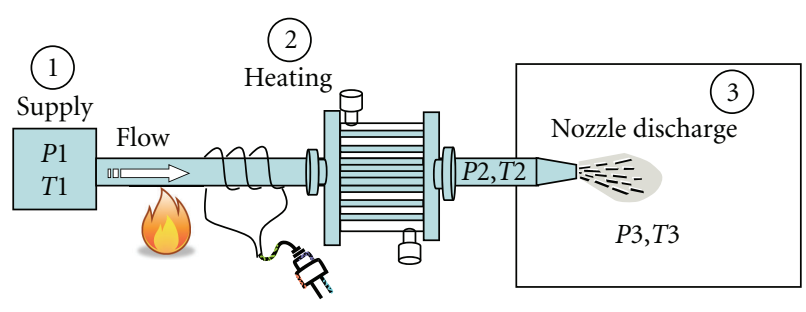

FIGURE 7: Illustration of flow process to create effervescent atomization by boiling at the point of injection [18].

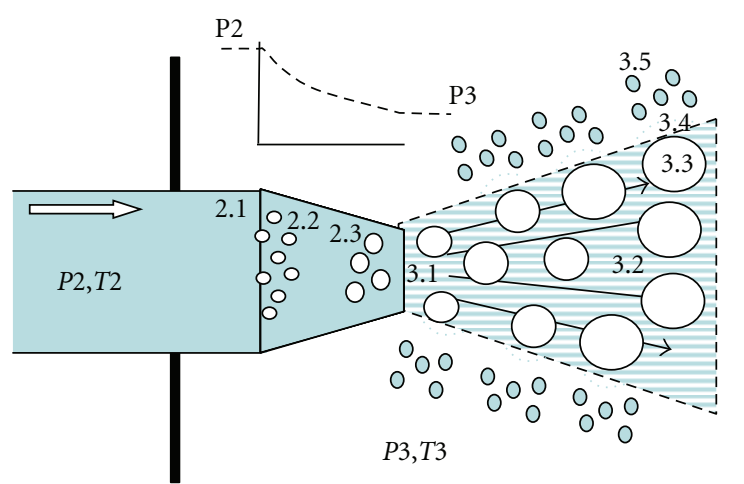

FIGURE 8: Illustration of the physical process of effervescent atomization by boiling.

(4) The water begins to increase in velocity as the flow area is reduced upon entering the nozzle (2.2); increasing velocity reduces static pressure based on fluid dynamic principles. If heated sufficiently, very small bubbles begin to form by nucleation as pressure drops below the saturated vapor point for the temperature of the fluid.

(5) The bubbles expand as pressure drops further in passing through the nozzle (2.3). The expanding volume forces the water to increase velocity which causes further pressure drop and increase bubble size.

(6) The bubbles expand even further on exiting the nozzle (3.1) and quickly exceed the initial volume of the water as the water exits (3.2).

(7) The expanding bubbles pass close to the interface (3.3) between the water flow stream and surrounding gas and burst through the bubble walls (3.4).

(8) The release of surface tension on bursting provides energy to disperse the surrounding water into very fine water droplets (3.5).

(9) The water discharges into the combustion chamber (3) at pressure $P 3$; temperature $T 3$ results from the mixing of the incoming fluid from the nozzle with the residual fluid and combustion process in space (3).

\section{Flash Atomization Demonstration}

In this study, the flash atomization concept is demonstrated on a small gas turbine used for research. The gas turbine

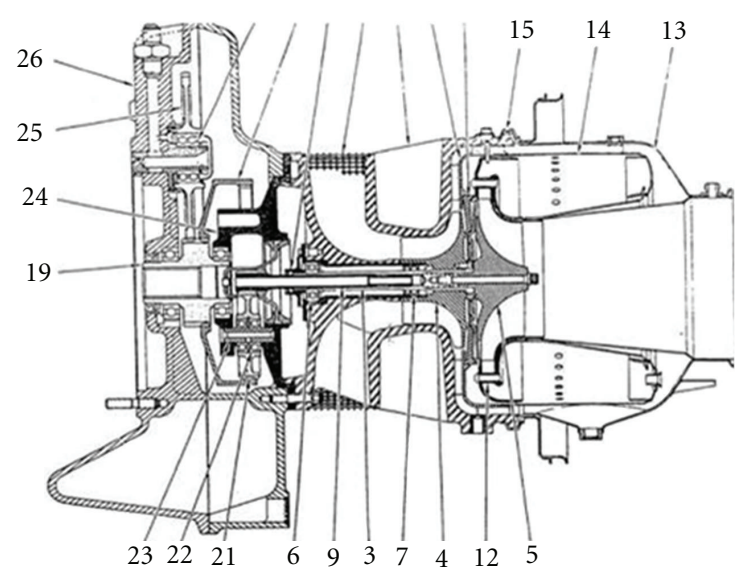

FIGURE 9: Schematic of SwRI research gas turbine.

is modified to accept water injected into the combustion chamber, and an electric heater is installed in the water supply line. The testing procedure is conducted as a series of tasks having ever-increasing complexity. First, a series of bench tests are conducted using the water injection nozzle to compare the atomizing effects of flash atomization, air blast, and both methods in combination with baseline water nozzle only. Then, tests are conducted to demonstrate the effects on the flame of water injection alone and with flash atomization using just the combustor section of the research turbine. Finally, comparative tests are conducted on the research turbine in operation.

The objectives are to (a) confirm that combustion instability is related to deficient water atomization inside the combustor by testing in a SwRI research gas turbine and (b) confirm, by testing, that combustion instability can be controlled and improved by efficient effervescent atomization.

The gas turbine used for this research is a Titan-model manufactured by Solar Turbines Co. that originally used liquid fuel. It has been modified by SwRI to handle gas fuel by redesigning the fuel nozzles and the piping system. A cutaway of the SwRI gas turbine is shown in Figure 9. A water injection nozzle was fabricated for this test and is inserted to replace one of the six fuel injection nozzles. The test nozzle used is sized to represent the actual size of each water injection hole $(0.89 \mathrm{~mm}, 0.035 \mathrm{inch})$ in the industrial turbine nozzles.

\section{Bench Test Evaluation}

Before performing the water spray test inside the combustor, it is important to identify the conditions at which the effervescent atomization occurs. Parameters such as water temperature and water flow rate need to be established. First, water at room temperature is run through the nozzle. Then, effervescent atomization of the nozzle is achieved by heating water through the nozzle (using the 500-watt heater) to its flash point. Good atomization is achieved when the water temperature measured $208^{\circ} \mathrm{F}\left(98^{\circ} \mathrm{C}\right)$ and the flow rate is $5.7 \mathrm{~L} / \mathrm{hr}$ (1.5 gallons per hour). Figure $10(\mathrm{~b})$ shows 


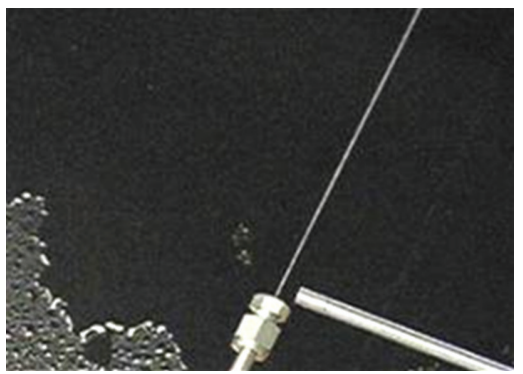

(a)

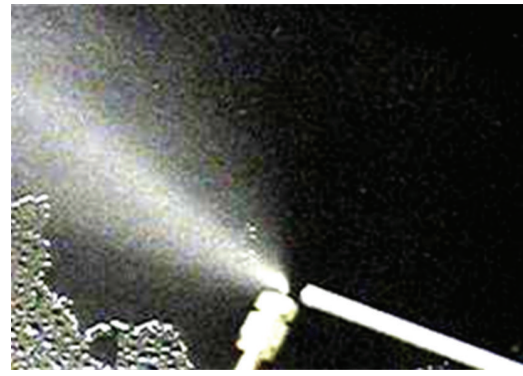

(c)

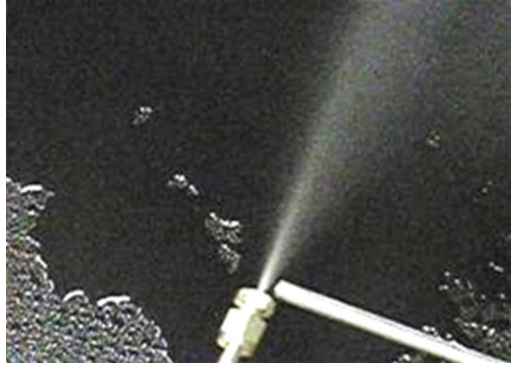

(b)

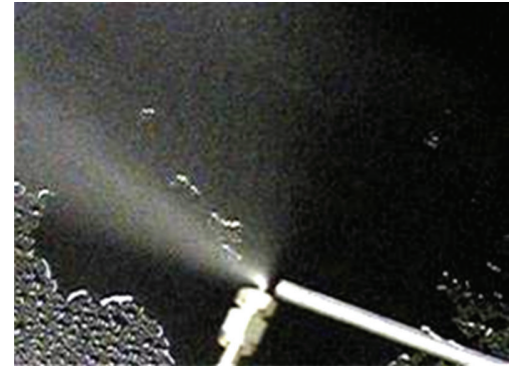

(d)

FIGURE 10: Water atomization. (a) nonaugmented nozzle, (b) flash atomization alone, (c) air-jet blast alone, and (d) flash atomization plus air blast.

the effervescent atomization achieved. It is clear, that the previous steady stream (Figure 10(a)) of water is now a spray of mist (very tiny water droplets).

The next task investigates the effects of air blast on the effervescent atomization process. An air nozzle is positioned perpendicular to the water injection in order to enhance atomization. Figures 10 (c) and 10 (d) compare the nozzle discharge with the air-jet at $100 \%$ for the flow condition mentioned previously. It is clear from the figure that, with the air-jet on, there is a considerable difference in the atomization behavior for the air-jet blast alone and the airjet blast with flash atomization. For the air-jet blast alone (Figure 10(c)), the water atomization appears to be sprayed but not spread out; whereas for the air-jet blast with flash atomization (Figure 10(d)), the water atomization is much more dispersed and spread over a larger surface area. The size of the water droplets for the air-jet with flash atomization appears to produce considerably smaller (misty) droplets.

\section{Research Turbine Demonstration}

The research gas turbine is modified and used to perform the realistic water injected combustion testing. The nozzles and the piping system were refitted to accommodate the current test. Figure 11 shows the gas turbine used for this part of the experiment. The following data is recorded for each test: combustor casing vibration, combustion chamber pulsation, compressor discharge pressure (CDP), exhaust gas temperature (EGT), fuel gas flow, water flow, water heater inlet temperature, water heater outlet temperature, and rotor speed.

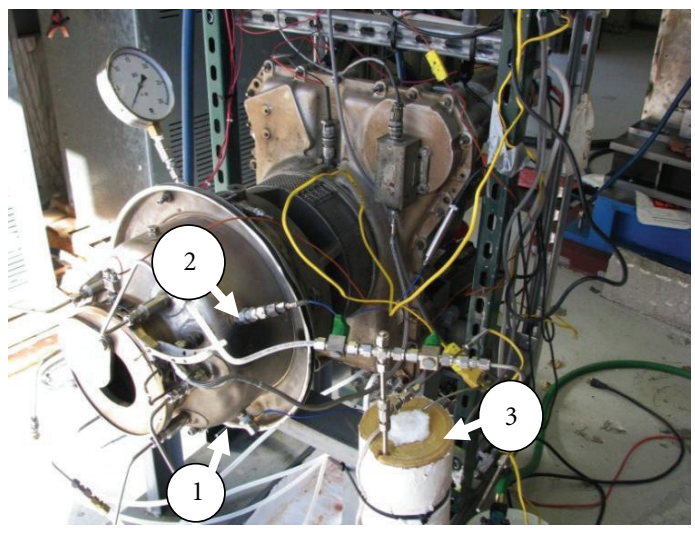

FIGURE 11: Gas turbine used for experimental studies; (1) vibration sensor, (2) pulsation sensor, and (3) water heater.

The operating combustion pressure and temperature are raised by partially restricting the exhaust with a variable orifice cover to impose load on the turbine. It is worth noting that injection of water reduces exhaust gas temperature (EGT) and increases the fuel gas flow required to maintain speed. This is an expected result.

The relative combustion acoustic performances are conducted for the specific conditions listed in Table 1. The final testing is conducted at two different general conditions: $55,000 \mathrm{rpm}$ and $62,000 \mathrm{rpm}$ which represent different loads and flow rates. Testing at the lower speed focuses on repetitive tests to evaluate variability in the data and confirms mean values for conditions with no water injection (dry), with cold water injection (wet), and with water heated to 
TABLE 1: Test operating points.

\begin{tabular}{|c|c|c|c|c|c|c|c|}
\hline $\begin{array}{l}\text { Speed } \\
\mathrm{rpm}\end{array}$ & Test number & Test name & $\begin{array}{c}\text { EGT } \\
\text { Deg C }\end{array}$ & $\begin{array}{l}\mathrm{CDP} \\
\mathrm{KPa} \\
\end{array}$ & $\begin{array}{c}\text { Water flow } \\
\mathrm{L} / \mathrm{hr}\end{array}$ & $\begin{array}{c}\text { Temp water } \\
\text { Deg C }\end{array}$ & $\begin{array}{c}\text { Gas flow } \\
\mathrm{m}^{3} / \mathrm{hr}\end{array}$ \\
\hline \multirow[t]{13}{*}{55000} & 1.1 & Dry 1 & 530 & 55.2 & 0 & 0 & 9.06 \\
\hline & 1.2 & Wet 1 & 510 & 55.2 & 15.1 & 0 & 9.3 \\
\hline & 2.1 & Dry 2 & 530 & 55.2 & 0 & 0 & 9.06 \\
\hline & 2.2 & Wet 2 & 510 & 55.2 & 15.1 & 0 & 9.3 \\
\hline & 3.1 & Dry 3 & 530 & 55.2 & 0 & 0 & 9.06 \\
\hline & 3.2 & Wet 3 & 510 & 55.2 & 15.1 & 0 & 9.3 \\
\hline & 3.3 & Eff. 4 & 510 & 55.2 & 15.1 & 0 & 9.06 \\
\hline & 4 & Dry 4 & 533 & 55.2 & 0 & 0 & 9.3 \\
\hline & 5 & Eff. 5 & 509 & 55.2 & 12.1 & 111 & 9.6 \\
\hline & 6 & Dry 6 & 522 & 55.2 & 0 & 0 & 9.06 \\
\hline & 7 & Eff. 7 & 513 & 55.2 & 12.1 & 112 & 9.6 \\
\hline & 8 & Dry 8 & 518 & 55.2 & 0 & 0 & 9.06 \\
\hline & 9 & Eff. 9 & 509 & 55.2 & 12.1 & 112 & 9.6 \\
\hline \multirow[t]{5}{*}{62000} & 10 & 62 dry 10 & 529 & 55.2 & 0 & 0 & 9.9 \\
\hline & 11 & 62 eff. 11 & 529 & 62 & 9.5 & 120 & 9.9 \\
\hline & 12 & 62 eff. 12 & 526 & 62 & 13.2 & 120 & 10.2 \\
\hline & 13 & 62 eff. 13 & 520 & 62 & 13.2 & 105 & 10.2 \\
\hline & 14 & 62 wet 14 & 514 & 62 & 13.2 & 65 & 10.2 \\
\hline
\end{tabular}

the point of effervescence. Testing at $62,000 \mathrm{rpm}$ does not only focus on confirming that the general trends discovered at 55,000 rpm hold true for a different condition, but also explores the relative effects of increased water temperature and flow rates.

It is important to assure that the water is close to an effervescing state at the flow rate used in this test before it enters the combustion chamber. A double valve/nozzle system is utilized. First, the valve for the water outlet into the combustion chamber is switched off, and the heated water is diverted to a water nozzle open to atmosphere. This nozzle is the same size as the one in the combustor. Once good atomization is confirmed visually, the valve to the open nozzle is shut off and the valve to the combustion chamber is opened. This ensures that the water entering the combustion chamber is fully atomized.

Several data processing steps are necessary to more clearly define the effects of water injection and atomization on combustion stability. Combustion is inherently a chaotic process, that is, there is a fundamental effect of acoustic resonance, but its excitation is by random energy release caused by vortices in fuel air mixing and in production of steam pulses as water droplets evaporate. Thus, the raw acoustic frequency spectra allow distinguishing the various natural frequencies, but the spectral quality is not sufficient to quantify the relative magnitude differences between the three different combustion strategies tested. Figure 12 presents overlays of four sequentially recorded spectra for test point 3.1 (dry combustion) and four sequentially recorded spectra for test point 3.2 (wet). As can be seen, high acoustic responses are found at $100 \mathrm{~Hz}, 1400 \mathrm{~Hz}$, and $3000 \mathrm{~Hz}$ for each condition, but it is difficult to clearly differentiate the magnitude differences.

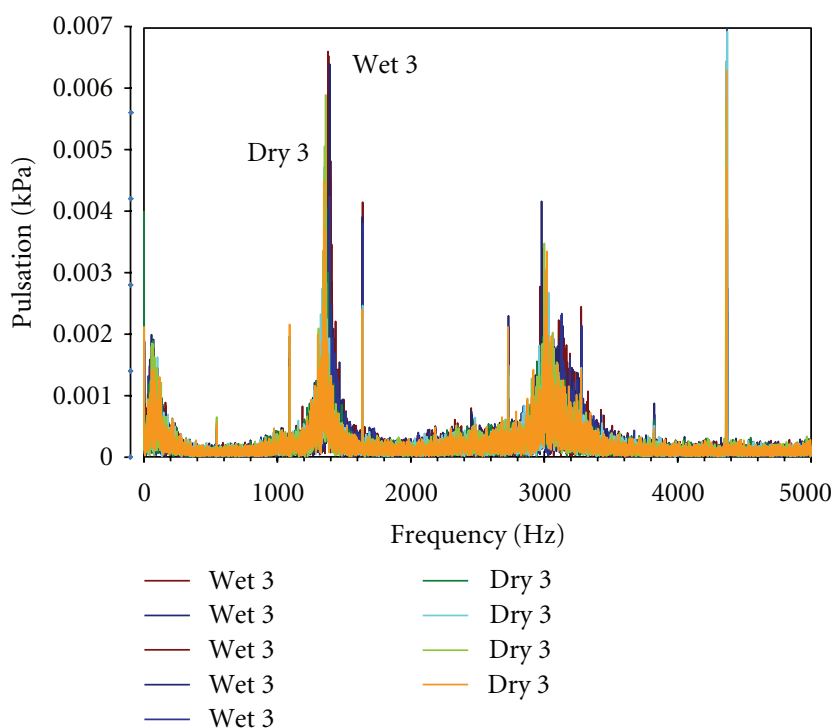

FIGURE 12: Comparison of raw frequency spectra wet versus dry.

By zooming in to focus on each specific acoustic frequency in Figure 13, a little better definition is noticed, but still not sufficient for comparative quantification. A procedure is developed based on acquiring and averaging 100 sequentially recorded spectra that are then smoothed by a moving average that covers $40 \mathrm{~Hz}$ band. The results are presented in power spectral density (PSD) units $\left(\mathrm{psi}^{2} / \Delta \mathrm{Hz}\right)$ on Figure 14. The resultant spectral trends are robust and sufficiently consistent to represent the relative differences in acoustic excitation inherent in each combustion condition (dry, wet, and effervescent). 


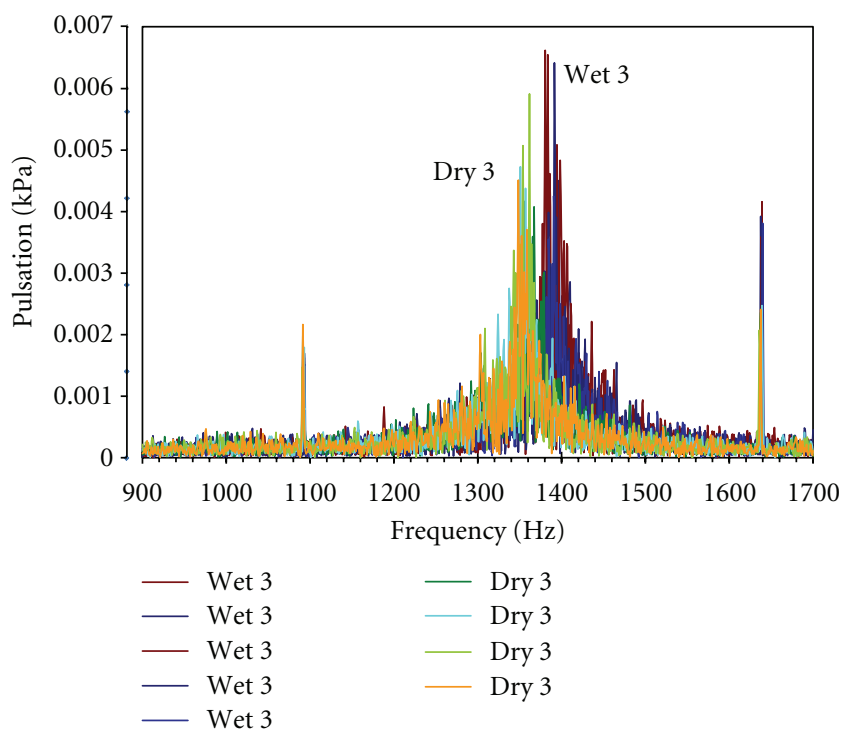

FIGURE 13: Comparison of raw frequency spectra wet versus dry focused on $1400 \mathrm{~Hz}$ mode.

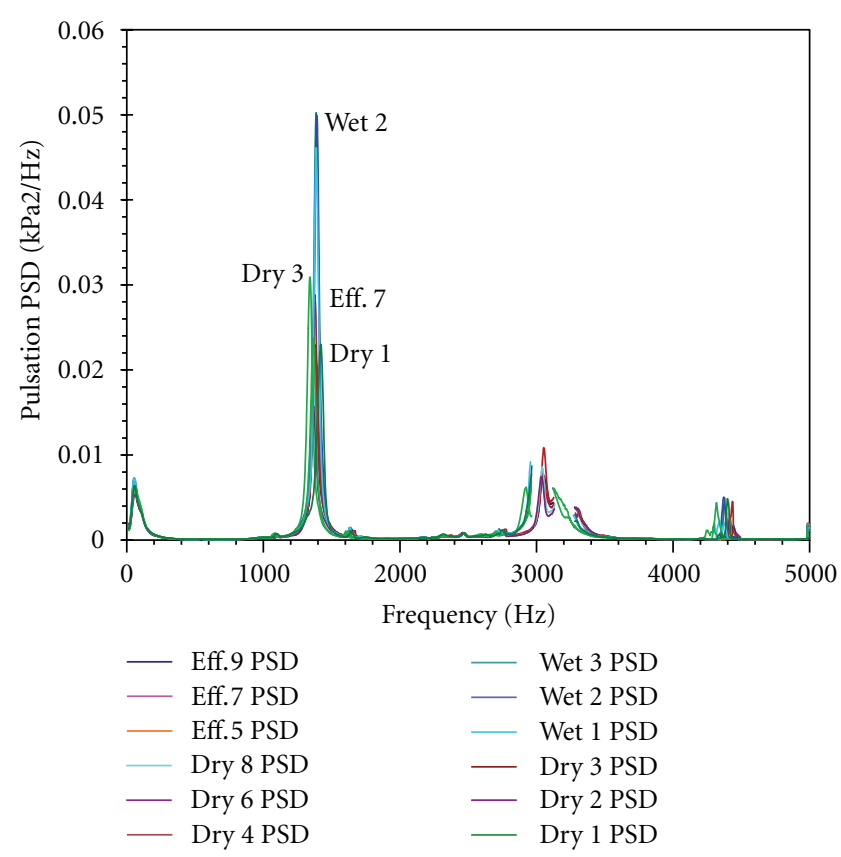

FIgUre 14: Composite of all pulsation PSD spectra for the 55000 RPM condition.

As all significant responses (100, 1400, 3000, and $4400 \mathrm{~Hz}$ ) show little or no variation between the different conditions except for the response near $1400 \mathrm{~Hz}$, the focus is narrowed on the frequency range between 800 and $1800 \mathrm{~Hz}$ (Figure 15). The data processing method, applied over this reduced frequency range, proves sufficiently robust to evaluate the effective pulsation energy level differences between each test. As can be seen, the peak pulsation levels are well grouped for the wet injection condition while, the

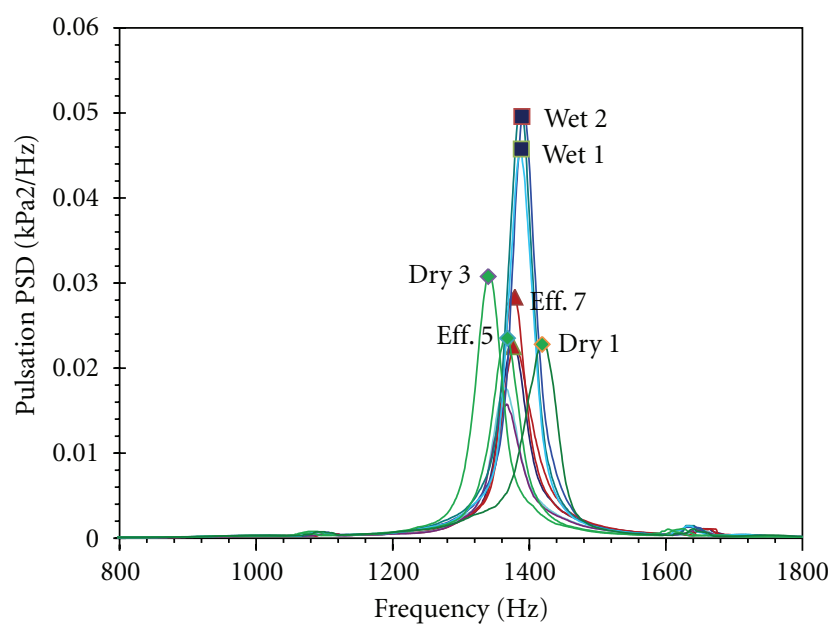

FIGURE 15: Expanded scale pulsation PSD spectra at 55000 RPM to examine levels near $1400 \mathrm{~Hz}$.

pulsation levels are lower and not easily distinguishable between the dry and effervescent injection conditions.

A comparison of the peak $1400 \mathrm{~Hz}$ pulsation levels for each condition tested at $55000 \mathrm{rpm}$ is summarized in Figure 16. This figure illustrates the following salient features in the data.

(i) The pulsation levels for each condition are relatively self-consistent for tests conducted at the same operating condition.

(ii) Standard deviations are $5 \%$ for the wet condition, $11 \%$ for dry, and $6 \%$ for the effervescent injection tests compared to mean levels.

(iii) The differences in pulsation levels at each condition are significantly greater than the data deviation and 


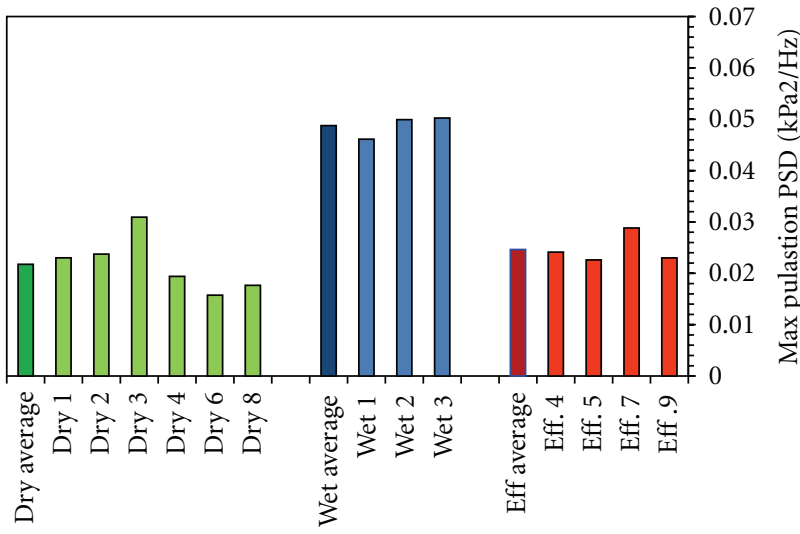

FIGURE 16: Comparison of peak pulsation energy for dry, wet, and effervescent injection at 55000 RPM.

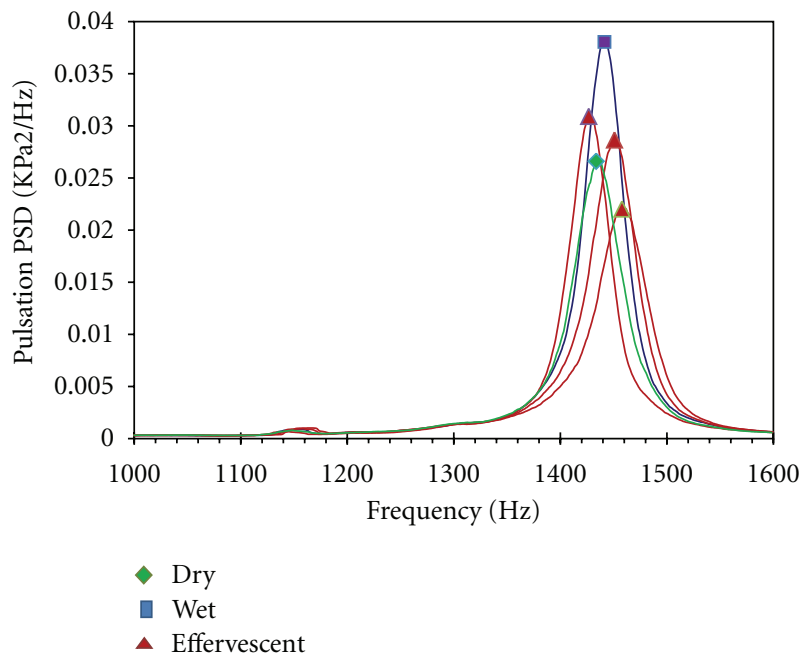

Figure 17: Comparison of pulsation spectra at 62,000 RPM.

can be reliably used to represent the effective differences in excitation levels.

(iv) The data represents the expected increased excitation by water injection and the benefit gained by effervescent injection.

As the dry and effervescent levels are almost the same, the application of effervescent atomization should reliably mitigate the increased pulsation caused by water injection. Testing near maximum speed, $62000 \mathrm{rpm}$ produced higher compressor pressures, higher exhaust gas temperature, and higher pulsation levels. The relative differences between dry, wet, and effervescent injection are similar to the results observed at $55000 \mathrm{rpm}$, however, see Figures 17 and 18. This provides confidence that the trend carried over a variation in operating conditions.

An additional objective of this test is to explore the effects of variation in water temperature and flow rate. Figure 19 shows that pulsation trend decreases with increasing temperature up to a point. Above that point, the water will vaporize in the supply line, and it is likely that steam will choke at the

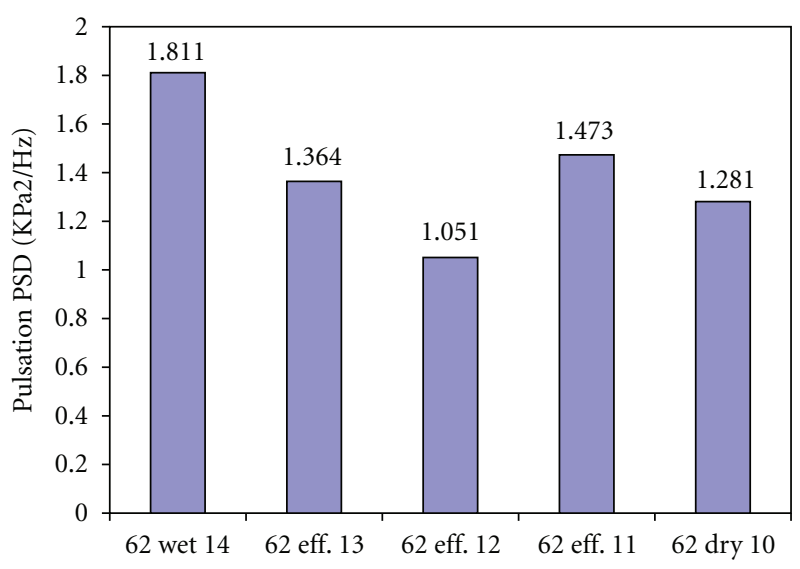

Figure 18: Peak pulsation energy for dry, wet, and effervescent injection at 62,000 RPM.

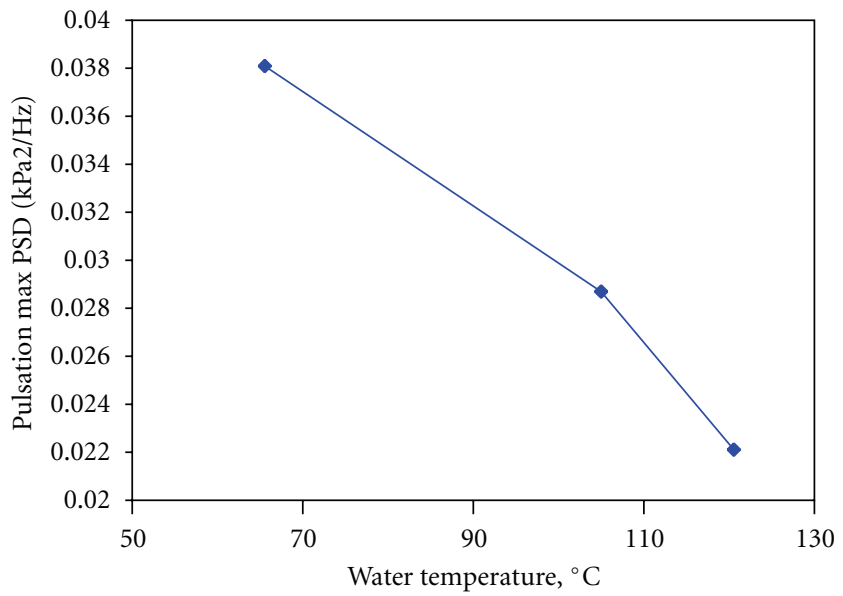

FIGURE 19: Trend of peak pulsation energy with water injection temperature.

orifice and limit the mass flow amount that can be delivered which will reduce the $\mathrm{NO}_{X}$ control effects.

In summary, combustion pulsation level with water injection rises significantly compared to base-line dry combustion levels for both the research turbine and industrial gas turbine. Introducing thermal energy into the water creates, steam flashing at the nozzle and combustion pulsation reduces to the base line (dry) level. At higher thermal energy input, more steam flashes at the nozzle, but no further reduction in pulsation is noted. Thus, only a small fraction of water needs to flash to adequately atomize the remainder. At much higher energy input levels, flashing begins to occur prior to exiting the nozzles which results in lower water flow rates and reduced ability to control $\mathrm{NO}_{X}$.

\section{Conclusions}

The investigations of the combustion pulsation problems, including the results of latest laboratory testing, confirm the following basic findings. 
(1) The research turbine tests demonstrate that pulsation energy at the acoustic fundamental natural frequency is more than doubles with water injection. This effect confirms the findings of the tests conducted on the industrial gas turbine.

(2) Testing confirms that combustion pulsation can be reduced to dry levels by effectively atomizing the water by an effervescent process.

(3) Testing also confirms that effective flash atomization can be achieved by bringing the water temperature to just below its boiling point at the point of injection.

(4) The addition of heat beyond that required for obtaining flash atomization adds little benefit.

(5) Increasing heat input to the point that water flashes before reaching the nozzle causes the flow to choke which dramatically reduces water injection which likely reduces the ability to control $\mathrm{NO}_{X}$ emissions.

(6) While the research turbine is much smaller than the industrial engine and its acoustic natural frequencies much higher, the test results for both engines show that the pulsation levels at first acoustic natural frequency are the most sensitive to water injection. With this similarity, the mitigating effects of effervescent atomization should be similar for both engines.

\section{Acknowledgment}

The authors would like to thank Cogeneration-Kraftwerke Management Steiermark GmbH (CMST) for funding this research work.

\section{References}

[1] O. Bolland and T. Veer, "Centenary of the first gas turbine to give net power output: a tribute to Ægidius Elling," in Proceedings of the ASME-Turbo Expo Conference, 2003.

[2] E. C. Wilcox and A. M. Trout, "Analysis of thrust augmentation of turbojet engines by water injection at compressor inlet including charts for calculating compression processes with water injection," Tech. Rep. 1006, NACA, 1950.

[3] J. S. Chin and A. H. Lefebvre, "Studies on internal-mixing airassist atomizers," unpublished Purdue report, 1992.

[4] S. D. Sovani, P. E. Sojka, and A. H. Lefebvre, "Effervescent atomization," Progress in Energy and Combustion Science, vol. 27, no. 4, pp. 483-521, 2001.

[5] A. H. Lefebvre, X. F. Wang, and C. A. Martin, "Spray characteristics of aerated-liquid pressure atomizers," Journal of Propulsion and Power, vol. 4, no. 4, pp. 293-298, 1988.

[6] A. H. Lefebvre, "Novel method of atomization with potential gas turbine applications," Indian Defense Science Journal, vol. 38, no. 4, pp. 353-361, 1988.

[7] J. S. Chin and A. H. Lefebvre, "Design procedure for effervescent atomizers," Journal of Engineering for Gas Turbines and Power, vol. 117, no. 2, pp. 266-271, 1995.

[8] B. Golovanesky and Y. Levy, "Suppression of combustion instability using an aerodynamically exited atomizer," in Proceedings of the 11th International Symposium for Applications of Laser Techniques to Fluid Mechanics, Portugal, 2002.
[9] R. J. Santoro, "High pressure combustion studies under combustion-driven oscillatory flow conditions," Tech. Rep. A765033, 1997.

[10] G. Yu, J. G. Li, J. R. Zhao, L. J. Yue, X. Y. Chang, and C. J. Sung, "An experimental study of kerosene combustion in a supersonic model combustor using effervescent atomization," in Proceedings of the 30th International Symposium on Combustion, pp. 2859-2866, July 2004.

[11] J. Y. Lee, E. Lubarsky, and B. T. Zinn, "Suppression of instabilities in liquid fueled combustor by variation of fuel spray properties," in Proceedings of the ASME Turbo Expo, pp. 139-147, June 2003.

[12] J. L. Chen, M. Wells, and J. Creehan, "Primary atomization and spray analysis of compound nozzle gasoline injectors," Journal of Engineering for Gas Turbines and Power, vol. 120, no. 1, pp. 237-243, 1998.

[13] A. Singh, M. Mehregany, S. M. Phillips, R. J. Harvey, and M. Benjamin, "Micromachined silicon fuel atomizers for gas turbine engines," in Proceedings of the 1995 9th Annual International Workshop on Micro Electro Mechanical Systems, pp. 473-478, February 1996.

[14] G. M. Faeth, "Structure and atomization properties of dense turbulent sprays," in Proceedings of the International 23rd Symposium on Combustion, vol. 23, pp. 1345-1352, 1996.

[15] J. A. Wünning and J. G. Wünning, "Flameless oxidation to reduce thermal no-formation," Progress in Energy and Combustion Science, vol. 23, no. 1, pp. 81-94, 1997.

[16] K. Mathioudakis, "Analysis of the effects of water injection on the performance of a gas turbine," Journal of Engineering for Gas Turbines and Power, vol. 124, no. 3, pp. 489-495, 2002.

[17] T. Kadota and H. Yamasaki, "Recent advances in the combustion of water fuel emulsion," Progress in Energy and Combustion Science, vol. 28, no. 5, pp. 385-404, 2002.

[18] "Procedure for injecting water into an essentially locked area and afterwards working a device," Austrian Patent no A704/2009, 2009.

[19] B. P. Husted, G. Holmstedt, and T. Hertzberg, "The physics behind water mist systems," in Proceedings of the IWMA Conference, Rome, Italy, 2004. 

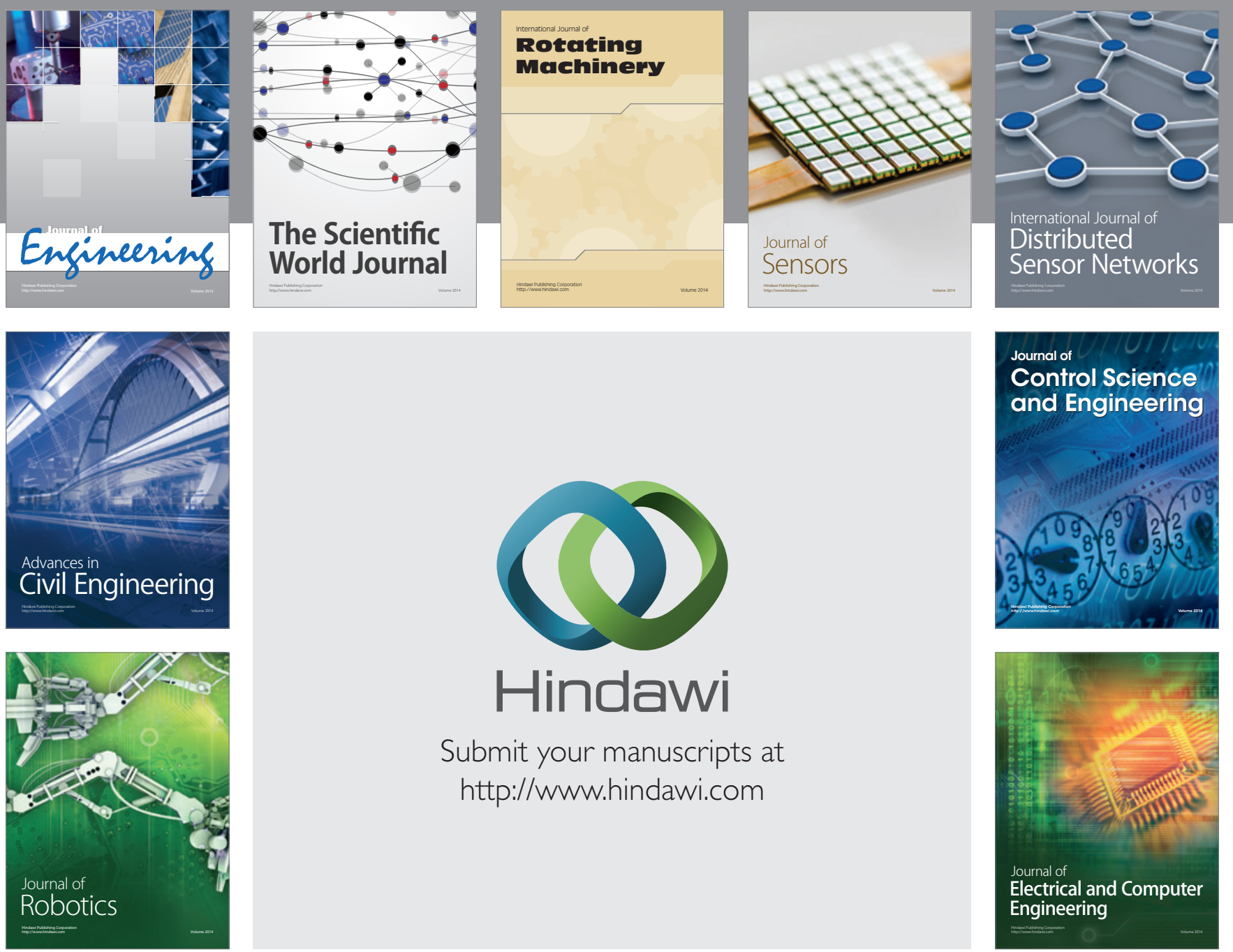

Submit your manuscripts at

http://www.hindawi.com
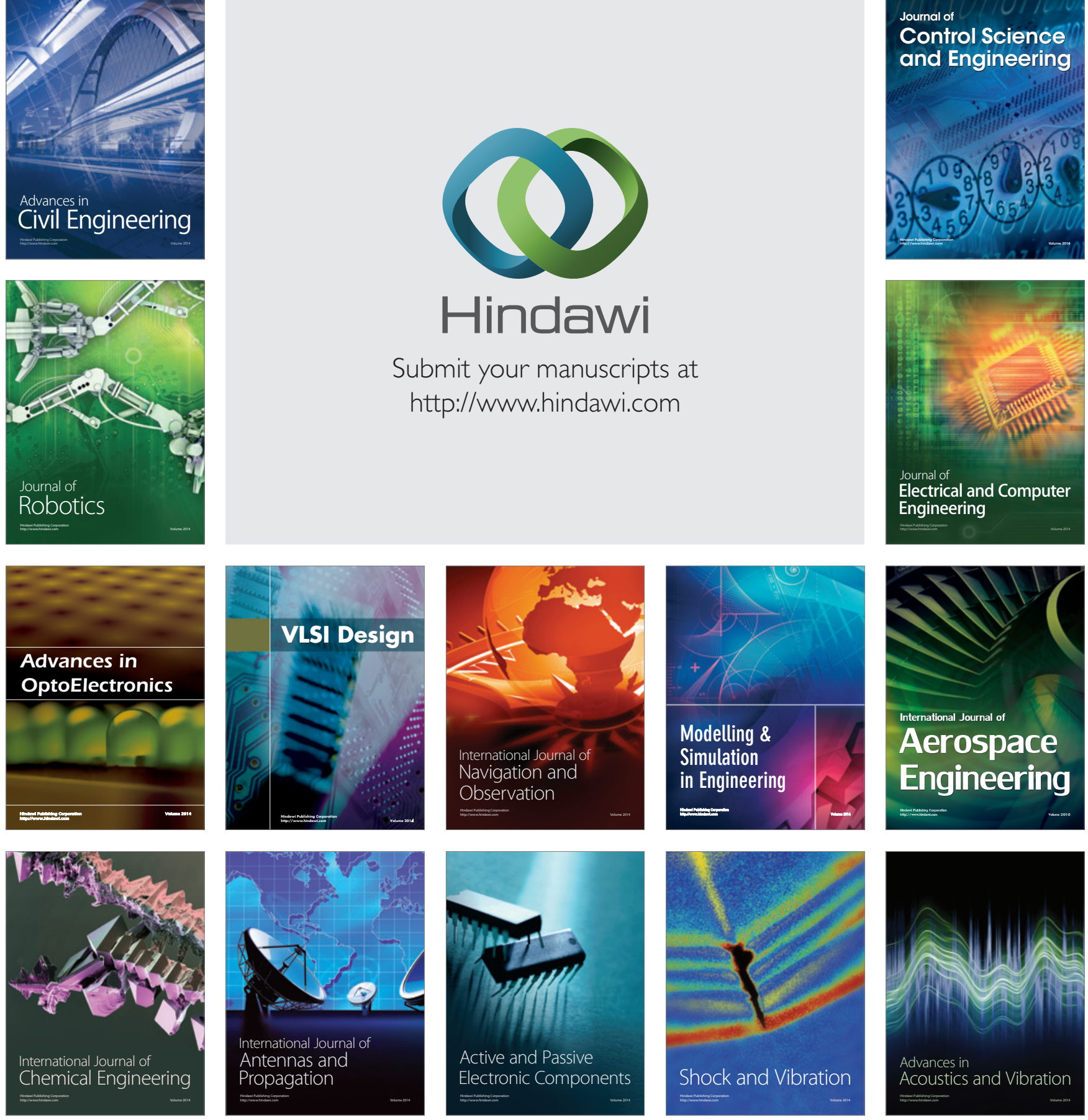